\title{
Pre-Natal and Post-Natal Birth Among Bulu from South Cameroon: An Ethno-Anthropological Reading of the Birth in Negro-Culture
}

\author{
Paul Ulrich Otye Elom* \\ University of Maroua, Cameroon
}

*Corresponding author: Paul Ulrich Otye Elom, Anthropologist, University of Maroua, Cameroon.

Received Date: January 21, 2019

Published Date: January 29, 2019

\begin{abstract}
Summary
As in all human communities, birth represents for socio culture Bulu a time when we e agree to the woman and newborn attention. This attention actually begins at the first moment of pregnancy and continues until complete weaning of the child who marks the entry of the latter and his mother into social normality. In this context, a real man is one who has children, the one who does not have to be relegated to a seat of jumping whatever his material wealth. The loss of a newborn or the birth of a stillbirth appears as a disease or better a crypto-disease. Taking as a field of study Bulu South-Cam eroun, this article watches that the birth in negro-culture is a social event whose specificity is apprehended taking into account the endosemia or sense of the inside.
\end{abstract}

Keywords: Birth; Pre-natal; Post-natal; Pregnant woman; Newborn

\section{Introduction}

Whatever the cultural universe, maternity is a delicate period of life when the woman and even the man are subjected to the constraints required by the various specialists of the health and the social entourage. This shows that beyond the physiological, birth also involves the cultural body. In the Bulu of South Cameroon, prenatal and postnatal women are asked to follow a certain number of practices inculcated by the cultural ethos to ensure that the child will come into the world without any problem and that his evolution after birth will be harmonious until the time of weaning, the key moment when the eye on him is less increased and marks in a way his entry into the normal social world, because making him an individual whose development is not more very worrying. Pre-natal and neo-natal shows nt and the birth ensures the survival of the social continuum or simply the perpetuation of cultural life. The debate we are embarking on in this article challenges the cultural elements of the society under study, which show that birth is a social phenomenon that can bring a holistic understanding of the community. With research techniques such as direct observation, in-depth interviews and a method of analysis based on Harold Garfinkel's ethno-methodological processes and Mbonji Edjenguèlè's ethno-perspective [1], processes related to ethno-anthropology, our paper will give a talk on the feeding of the pregnant woman, woof breastfeeding and newborn. A presentation on dietary and sexual prohibitions whose transgression can lead to the death of the child and sometimes of the mother. And finally, a presentation on the different social and medical uses to be respected in order to avoid a disharmony of the child's development. But before all that, let us establish a contextualization of certain concepts.

\section{Contextual clarification of some concepts}

It is important, for a better understanding of the scientific analyzes that we bring here, to highlight a number of key concepts that revolve around the theme of birth in a bulu context. As well, will we explain the concepts of pregnancy, birth, childbirth, breastfeeding, newborns?

\section{The pregnancy}

Among the Bulu, the gravid state is abum that can be translated literally by belly. We will say that a pregnant woman has no abum, she is belly. The verb to be here shows that the pregnant woman becomes what characterizes her. It therefore has no belly, it is the belly, which shows that it identifies with his pregnancy, the most 
distinctive sign is the prominence of this part of the body. It also takes the name ofmbubum, literally mean the venture. We can say that she is assimilated to what is in her belly, that is to say the baby she is carrying; which suggests that it is the being it carries in it that is more important or better on which the greatest attention is focused. Moreover, the belly, it must be said here, is in society under study the seat of life and good. It is, however, also the seat of evil, inasmuch as the Bulu believe that witchcraft is in the womb. The focus on the belly of the pregnant woman goes beyond the simple of visually, for the reason that we must ensure that the child born will be healthy and will not be subject to evil spirits all the time of pregnancy. It is commonly accepted here that when a child is born with unusual abilities, in the good or the bad sense, he was influenced when he was still in his mother's womb.

\section{Birth and childbirth}

From the verb born biae, birth abialé translates in Bulu the moment when the woman releases the child that she carries in her. Also, we use the same words to designate childbirth, for the simple reason that the two are indissociable. It is an important moment in the life of every female individual, as it requires special precautions to preserve the life of the mother and the baby. Generally, only the relatives of the pregnant women are present during that time, because we often feared that evil people $\mathrm{n}$ e $\mathrm{n}$ benefit to harm the child. In most cases, it is the mother of the mother-to-be who assists her and ensures that parturition is going well.

\section{The newborn}

To designate the Bulu child, use the word my which generally applies to all human beings who have not yet reached the weaning period. From then on, the child becomes Mongo until he reaches maturity. However, when it comes to just being born the baby is called nkenle my, or just nkenle. This epithet shows the fragility of the child at birth and shows that we must treat the child with all the possible precautions. It is usually when it comes to being born that one decides on the personality future, we want to give to the child depending on whether he is a boy or a girl. And this is the name we give it all takes an important. Indeed, we pay attention to the surname given to him, insofar as the individual is called to reproduce throughout his existence, the qualities and defects of the person whose name he bears Remember that being named after a newborn baby is an immense honor because it shows all the esteem you have for your parents. With the advent of Christianity, it is also important to choose a godfather to guide him in his spiritual life. This godfather is present at the baptism and is just as honored to have been chosen for this role.

\section{Breastfeeding}

Breastfeeding in bulu is said nyia'a, the word breastfeeding can be said nyananmy. This shows the process the mother uses to feed her child, because the mother is termed by the term nya. Menyan milk, which is also derived from the substantive nya, is the nourishing substance produced by the mother for her child. For the Bulu, breast milk is the exclusive food of the newborn, and the newborns are not happy about breastfeeding. This is only acceptable when the mother produces milk that may be deleterious to the health of her child, which according to this socio culture often happens, even if it has not yet been scientifically proven. Previously, when the mother died and there was no nanny to replace it, the child was fed with a product made from palm wine and other substances. Never mind, it has become clear in this cultural context that breast milk is the best food for ensuring a harmonious development of the individual throughout his life. Also, it is commonly accepted that the child who has not been fed breast milk will be in the future a jerk. The artificial milk being drawn from the cow, it is thought by transfer movement that the individual takes the "foolishness of the animal. Breast milk is also supposed to strengthen the bond between the mother and her child. As a result, those who have not taken it will not have respect for their mother. Some even think that non-consumption of breast milk will make the child a delinquent future. Moussa Maman gives a glimpse of a similar conception of mother's milk in the West African ethnic groups and asserts bluntly about cow's milk that:

Thus, currently, criminals, thieves or drug addicts are considered to be people who, in their childhood, have had bad milk. Some people even think that the behavior of young people who no longer respect authority or standards is due to bottle milk and canned condensed milk from Europe. In the years 1960-1970, the Guigoz and Nestlé milks were banned by the men who prevented their women from feeding their children at the bottle [2].

And to show the irreversibility of breast milk, the author pontifies: " the destiny of a child depends on the milk of his mother"[2].

\section{Cultural Practices Related to Birth in Bulu}

There are several cultural practices associated with birth in the Bulu community, we have noted here some that prove the worth of the child. These practices are observable before birth, during birth and months after birth.

\section{Requirements at the feeding level}

The prenatal and postpartum period asks the woman for certain prescriptions and proscriptions. With the aim of preserving the health of the mother and the child, because we know here, of the health of the mother depends that of the child, these requirements must be followed scrupulously, and the entourage is there to take care of it.

\section{Dietary prohibitions}

Many diet specialists, in this case dieticians, nutritionists and even nutrition anthropologists have often decried the dietary prohibitions that are encountered in Black African cultures. Besides, AMPLIFYHélène Pagezy:

In many subsistence societies, dietary prohibitions are more particularly concerned with animal species, which are rich in good quality proteins such as game. They apply more particularly to pregnant and breastfeeding women and to young children, categories that are biologically vulnerable because they have increased needs for pregnancy, breastfeeding or growth [...] These interdictions have been maintained thanks to their symbolic and social function [3]. 
However, we believe that in a bulu context, we must qualify these reproaches to the extent that the food prohibitions concern only certain foods, which, in most cases, are not even consumed regularly, and which in our opinion, to be criticized should be compared with all that is recommended to the woman in this context of consuming.

It is so prohibits the female individual of childbearing age from consuming halophane meat, opkwen. The animal produces a lot of drool, it is feared that the child is also born with drool. In the mosaic of food prohibitions found among Bulu, it is also required to the girl not to consume the casings of animals, to prevent the birth at birth, the umbilical cord strangles her baby. The ventral part of the pork can only be consumed here by women who are no longer of childbearing age, because, according to the Bulu, its consumption causes the child to have a prolonged closure of the fontanel and a long healing of thewound. umbilical cord. The meat of bubale, zip is also among the forbidden foods to the pregnant woman. According to the endosemic report that we have been given, the consumption of this food causes difficulties during childbirth, the risk of miscarriage and heavy bleeding.

Although this is optional, it is highly recommended that the pregnant woman not consume a fish that lacks her head, which is often the case during the all-female fishery called alok. During the fishing, if he is offered this type of fish, it must not accept, or at least if it pren d, should not eat, because usually there is a fish on which has been performed witchcraft, with the aim of killing the child whom she wears by mere jealousy on the part of her enemies. She can even lose your life if the " dose of witchcraft Is strong. The illness caught by this procedure is called mekaï and usually loses all the children it will have in the future if it is not treated. We will come back a little further.

To prevent the death of the child through witchcraft practices, pregnant women are advised not to consume turtle meat regularly used for harmful practices. By eating turtle meat that has undergone such treatment, the cervix is blocked during childbirth, causing the child to die from asphyxiation.

\section{Dietary requirements}

It should be noted that apart from the few foods that it is strictly forbidden to consume, the woman can consume all the foodstuffs that generally enter into the daily food of the Bulu. However, the pregnant woman or woman who has just given birth is asked to follow a specific diet. We thus agree with François Lupu, who worked for him at the Tin Dama in Papua New Guinea that "... the maintenance of a diet is central to the smooth progress of the pregnancy process " [4]. She has to take a lot of fat in order not to lose weight, because during these periods, she spends a lot of energy, and then, it is said here, she eats for two. A dish should not miss in its daily menu: he it is the pkwem ésuk or dish made from cassava leaves and fruit pressed from the oil palm. These foods are supposed to keep the woman healthy by improving the quality of her mother's milk. Research that we have previously carried Vons [5] show that cassava leaves are galactagogue. In essence, when a woman has bad breast milk, there are three recipes to improve it. The first is a drink made from palm wine and the bark of the esombo tree (Rauvolfia macrophylla) or the bark of the abang (Milicia excelsa). You can also give it a special type of banana called a ban. The third recipe is the ripe banana-plantain compote mixed with the bark of the esso. It is therefore advisable for the lactating woman to drink palm wine from time to time in order to improve her breast milk.

\section{The baby's diet}

If it is true that at birth the child must exclusively have breast milk, except in special cases, as we have said above, it should not be forgotten that from the first months, he is made to taste hard foods to accustom him to the flavors of the dishes of his culture. It is therefore a question of proceeding in a certain way with its food socialization in a progressive way. However, the weaning that imposes a new food repertoire is a situation that cannot be ignored, because if it is poorly managed, the child catches diseases. Weaning, in bulu ntilane mon mebé (the prohibition of the breast to the child) has always been a problem in childcare practices. Igor De Garine notes the difficulties of weaning a child. Also, says he:

On another level, the human feeding behavior seems to meet the requirements of its physiology with difficulty, and it is even a field to characterize it compared to other animals: that of his very long childhood, during which his physical development is closely linked to his nutrition. It is well known that in traditional societies, infant mortality is high during the weaning period and this is probably one of the few universals in human nutrition [6].

Indeed, when a child stops taking breast milk, or takes it only occasionally, finding foods that will not be harmful to him is necessary. Beside the foods he will learn little by little to consume in order to integrate the social undivided, is a special dish given to him, and thanks to which, he can eat without much risk of getting diarrhea: it's about of a cake made from cassava, roasted crushed peanuts and palm oil referred angomo. In this dish however, care is taken to add a special ingredient: a powder made with sundried plantain peels. When they are completely dry, these skins are ground; the powder obtained is mixed with the other ingredients. The angomo is supposed to contain all the nutrients that the child may need. As for the powder added as an additional ingredient, it saves it from food poisoning and diarrhea. So, let's admit with Igor D e GARINE than:

Man and his culture are here substituting for nature, deciding according to the norms that are peculiar to each group, the moment of weaning and prescribing the foods that will have to be used by the baby. It is striking how few human societies have been able to develop or use a nutritionally appropriate weaning food [6].

\section{Medical and health requirements}

Before the child is born and after birth, Bulu has a set of sanitary precautions. In addition to the usual precautions of adopting a particular lifestyle in everyday life, the woman must take during these times, drugs that will promote an easy expulsion of the child and avoid miscarriage or premature delivery. The child also undergoes traditional medical treatment to prevent him from falling constantly sick or even losing his life during this delicate 
period. In this part of our work, we will discuss the medications taken by the mother and her baby. Then we will talk about a mekai called a spell called the Hijack, the purpose of which is to prevent the pregnancy from coming to term.

\section{The medications of the mother and the child}

The sanitary precautions taken around the birth of a child among the Bulu of South Cameroon require the taking by the mother and the baby, a set of drugs some of which will be revealed here. These medications taken before and after parturition are composed mainly of herbs and bark that will be taken per os and purge mainly.

We can for example quote the bark of the tree éyen (Distemonanthus benthemianus), which ground, is consumed by the pregnant woman to clean the skin of the baby. Also, it will come to the world without skin problems, including dermatological redness. We can also mention the bark of the éyon. M élangée to toughened cooked cassava, it is used to avoid the child too swimming in amniotic fluid, which can cause birth complications and make the asthmatic child later. At birth, a decoction made from oyeyia grass and the fragrant maniguette called ndong is given to the child to make him regurgitate the impurities he could have swallowed in the belly of his mother. It should also be remembered that the fragrant maniguette, mixed with peanut paste, is consumed by the child so that his fontanelle closes quickly. If we had to be exhaustive, we could produce an entire book on these drugs, so let us remember that there are several other drugs around the birth to preserve the health of the child and his mother.

\section{The curse Ka Ed Me}

As we noted above, the curse meka e is caused by the eating of fish which were performed witchcraft. When the mother does not lose her life, she loses at best that of her baby and that of others that she will give birth at a later time. This disease also called edip is part of the crypto-diseases [7] at the Bulu. According to the information from traditional healers, the meka ed is actually inoculation in the body of the wife of a mystical worm called $\mathrm{n}$ set meka meka worm é or é. This worm corrodes the woman's genitals, preventing her from having healthy children. It is therefore possible to find women who have already made several miscarriages or whose babies die a few days after birth. Here is how it is treated if we stick to our field data.

The first phase of treatment begins with the laying of a hen on the head of the disease. It is from there that we detect the person responsible for the disease. If the chicken goes down on the right side, it means that her pain comes from her paternal family; and conversely, if it goes down on the left side, it is because the evil comes from the maternal family. However, in the latter case, it is admitted that the perpetrator had an accomplice in the paternal family of the victim, given the fact that an individual is virtually untouchable in his maternal family among Bulu. In an African context, the person in charge of the meta-mal is most often a close friend of the bewitched. And even when it is a person with whom we have no family acquaintance, it almost always passes by a close to do harm. In any case, to ensure the success of the treatment, it is essential to know who initiated the disease. to neutralize if he intended to try again. It also allows you to wipe out your power by revealing it in plain sight. It is therefore a question of following the logic according to which, a recunnu criminal is always diminished. Also, the unveiling of the culprit marks the beginning of the actual treatment. This is where an ethno-drug orethno-drug [8].

The ingredients of this dish are: pumpkin seeds, fish without scales and special herbs that the tradipratic did not reveal, held by the seal of professional secrecy. By fish without scales or kos mesom we mean fish such as catfish and catfish. Crab and you Crevet also part of it.

When cooking is finished, the traditional healer makes incantations and then the patient consumes it, which will allow him to regain his reproductive health. The post-treatment phase is characterized by a ban on food. The woman who was the victim of mekaé should no longer cons o mmer fish without scales. If it transgresses this prohibition, the disease will resurface and be even more serious. We noticefrom the outset that it is the fish without scales that is used as an ingredient in the preparation of the mealremedy which is then peremptorily forbidden to the patient, which leads to the conclusion that it plays in fact a homeopathic role. The disease is therefore in a state of latency, since, as soon as the ichthyological food prohibition It is broken, it resurfaces with more virulence and is often fatal to the patient.

\section{other cultural representations related to birth at bulu}

To present a more complete presentation on birth-related practices in bulu countries, it seems appropriate to mention another socio-cultural phenomenon observable during this period. We introduce our subject here by talking about the day of delivery. According to Bulu sapiential memory, the woman should not give birth on a moonlit night, otherwise the child will be very fat and will have difficulty passing through the cervix, which will obviously cause dementia. huge difficulties in childbirth. It has been reported to us that women who give birth during this period usually give birth by caesarean section. Before, before this medical technique was known in Negro culture, it was common to lose the life of the mother.

We can go back to the breast milk to say that during breastfeeding, the woman must avoid being wet by the rain, because we think here, if any, her milk will be bad for her child. It is further forbidden to drop breast milk on the sex of the child when it is a boy; in which case, the latter will be reached in adulthood of sexual asthenia.

It should also be noted that it is forbidden for a woman who has just given birth to have sex until the child is weaned. In case of transgression, the child gets a disease called dan my. The prodromal observations of this disease are: a lack of appetite, weight loss, chronic diarrhea, which can lead to the death of the baby, if it is not supported quickly.

It is imperative to make a presentation on the mandatory donation of food after the birth of the child. There is a food donation here called akon metyi (literally: the blood spear; akon = lance and metyi = blood). In terms of food, it is mainly the gift of red wine that a man must give to his in-laws when his wife or his concubine has 
just given birth to a child. This wine $\mathrm{r}$ ed, represents the blood shed by the woman during childbirth. It is therefore considered that it is the man who is responsible for the shedding of blood, since it is he who put this child in the belly of the girl. An interpretation of the name given to this donation of food also makes us understand that it has a sexual connotation. The word launches, akon represents by analogy, the phallus which, piercing or if one wants to penetrate the sexual organs of the woman has caused later blood shedding. It is also a kind of sacrifice made by the father of the child, so that the latter may be blessed by his maternal parents and thus experience a harmonious development. the metyi akon must be done if we want to avoid problems in the child.

Beyond the akon metyi, the father must also distribute food and alcoholic beverages to his own family as a sign of rejoicing. It is also an obligation, because if we refer to one of our informants, to give food and drink after the birth of his child, is a way to bless the child, to get the group to accept it. If you do not do it, some people may get angry, which is bad for him. The birth of a child is also often characterized by giving a number of gifts to parents, which makes the blessings even more important. However, parents must give food and / or drink to those who come to visit him.

\section{The Outline of an Ethno-Anthropological Analysis and Interpretation of Birth in a Context of Bulu}

The cultural items we observe around birth among the Bulu of South Cameroon are quite revealing for the ethno-anthropologist and are therefore likely to propose a debate starting from referring to this discipline.

\section{Birth and feeding}

Among Bulu, we found a set of prohibitions and dietary requirements around the birth of the child. It should be known that in a bulu context, the link between the child and his mother is practically consubstantial. Also, what his mother consumes, the baby who is in the womb or who has just been born consumes it too. However, forbidden or prescribed foods obey the law of similar or the principle of "I become what I eat "Evoked by [7] in his socioanthropology of the eater. By eating forbidden foods, the woman makes her child take on the symbolic characteristics of the food, with the emphasis on the negative side. Indeed, she is already fashioned, a " final product So that these negative characteristics do not have much impact on her, compared to her baby who is only at the beginning of her construction as a human being in her own right. At the same time, it is supposed to take the positive side of the prescribed foods.

\section{Birth and sexuality}

After the birth of her child, the woman is asked not to have sex for a while. This is even more deleterious to the health of the child if these relationships are maintained with an individual who is not the parent of the latter. The purpose of sexual intercourse in Bulu country and in most Negro cultures is above all procreation; it is also what signals [8]: “ Thus the sexual act or the procreation would be a cooking, where the ingredients brought by the two partners, are " cooked To the fire that is the woman, to give shape to the child ". Sexual intercourse is even required during pregnancy, because it is believed here, they give more strength to the unborn child. Also, to maintain them while the child has just been born is like wanting to give him a baby while he still needs all the affection of his mother.

It is also to put him in competition with his father who, nevertheless, must allow the intimate bond that mother-child maintains to be forged without interfering, to the extent that the newborn needs that all the attention is granted to him. The illness dan mon is therefore a way of showing his discontent to his parents who do not give him all the necessary love for his blossoming. In falling sick and in some cases when dying, the baby expresses that he is not welcome and prefers to return to his creator.

\section{Birth and witchcraft practices}

In a bulu context, to have no children is to remain a zézé word, that is to say a man who does not have a great social value. And usually, when a couple cannot make a child, it is always easy to blame the woman. Also, is it imperative for every female individual to give birth, since it was even possible before to bring a man's wife

The woman of childbirth by occult means is to hurt her, which will traumatize her for a long time. It is therefore one of the most terrible afflictions for a woman to kill her child or prevent him from giving birth. The sorcerer will take even more pleasure in inflicting such a curse than giving death to his enemy, to the extent that he can see it suffer under these eyes. In many cases, those who use the occult powers to harm their enemies prefer to attack their offspring, aware that it can be more distressing than hurting them directly. In other cases, it is possible to "spoil the child" while in the belly of his mother. It is thus admitted that some children who come into the world with particular flaws have suffered the evil action of sorcerers. This is the reason why the pregnant woman is asked not only to obey certain prohibitions and prescriptions, but also to follow a set of prenatal and postnatal treatments. If it is true that these treatments are pheno-medical, it must be admitted that they also bring on the scene crypto-medicine.

\section{Birth, the health of the child and the mother}

Pregnancy shows that this is a time when a whole series of measures must be taken to ensure the health of the mother and her child. Also, aware of the vulnerability of these two individuals, sociocultural bulu always focuses on preventive health practices. A certain interpretation of these practices leads us to say that to preserve the health of the mother and the child is to ensure the continuity of life; the mother being the one who gives it and the child the one who determines its perpetuation. These practices are therefore anthropo-socio-cosmic, because they concern at the same time the physical health of the individual (that of the mother and her baby), the health of society (by ensuring the perpetuation of life) and even the health of the environment (the supernatural powers often mentioned reside there and maintain an intimate link with the members of society). Also, losing the child and / or his mother, is a real disruption in the harmony of society; disturbance that often requires rituals for the latter to regain serenity. This leads us to recognize that: Among Beti, as in many cultures, there is only one word -mvo- to indissociably signify good individual health and community peace in harmony with the world. Correlatively, 
misfortune, bad luck, concern from a certain degree of gravity, even more than the individual, the whole of his group, which will mobilize to solve the problem, a large number of symbolic and economic processes [9].

\section{Conclusion}

To conclude this article, we will say that practices related to the birth of a child in bulu socioculture are an imperative to ensure the maintenance of maternal and child health. Traditional childcare, rituals, prohibitions and dietary prescriptions, beliefs around birth fully justify the importance that the society under study gives to the harmonious development of the child. Development that is taken care of from the first moments of pregnancy, to the weaning of the child after birth. The child thus ensures the future of the society, since it is called to ensure later the succession of the adults in the social continuum. It is therefore necessary that he be healthy from birth.

\section{Acknowledgement}

None.

\section{Conflict of Interest}

No conflict of interest.

\section{References}

1. Fischler C (1990) The Homnivore: The Taste, the kitchen and the body, Paris, Odile Jacob, France.
2. Fokou G (2001) The Practices religious the West-Cameroon: contribution to An Ethnology of Cults of the terroir Bamileke Memory of Master, University of Yaoundé, Cameroon.

3. Garine DE (1979) Culture and nutrition. In: Claude Fischler (Ed.) For an Approach bioculturelle of power supply, $\mathrm{N}^{\circ} 31$, Paris, France FirminDidot, Pp.70-90.

4. Laburthe Tola Ph, Warnier JP (1993) Ethnology Anthropology Paris, France.

5. Lupu F (1996) Pregnancy and feeding in Tin Dama. East Sepik Province. Papua New Guinea, In: Power/Food, Geneva, Library Of Ethnomedicine pp.75-85.

6. Mbonji Edjenguèlè's (2005) The ethno-perspective yes, The Method of Speech Of ethno-anthropology Cultural, Yaoundé, presses University of Yaoundé, Cameroon.

7. Moussa Maman (2005) The milk Maternal, Food Sacred, Power of life, Power of Death, In: Care, Pediatrics-childcare, $n^{\circ} 222$, pp. 35-37.

8. Otye Elom Pu (2012), food and health in southern Bulu-Cameroon in contribution to an ethno-Anthropology Of the food-remedy, Thesis of PhD/Ph.D., University of Yaoundé, Cameroon.

9. Pagezy H (2006) Food and Growth. Should Condemn the Prohibited Food? in: Acts of Conference of Group of Anthropologists, Anthropol. N ○11, Pp.119-127.

10. [1] We Oppose Crypto-Disease To pheno-disease. By pheno-disease We Hear A Disease Normal That Can Be cared for by Remedies Natural Yes in Going To the hospital, then that the crypto-Disease Is A Disease which has A Caused Hidden, Supernatural, « mystique ». C It Terms Borrowed to MBONJI EDJENGUELE, in his Book Health, diseases and Medicine African. Advocacy for the other radipraxies Published In 2009 press University of Yaoundé, Cameroon.

11. [2] Food Medication Own to An Ethnicity. 